\title{
Matemática, corpo e resistência cultural
}

\author{
Vanisio Luiz da Silva ${ }^{1}$ \\ Wanderleya Nara Gonçalves Costa ${ }^{2}$
}

\section{RESUMO}

Objetivamos com este artigo reorganizar e socializar reflexões acerca de elaborações e pensamento matemático que se manifestam cotidianamente em instituições de resistência cultural - negra. Para tanto, nos pautamos em pesquisas afiliadas ao programa Etnomatemática, nas quais os investigadores se debruçaram sobre processos cognitivos e de afetividade que afloram, por meio da corporeidade; da palavra e do gesto e da produção solidaria. Vale destacar que tais processos e modos são conhecimentos ancestrais e neles são reconhecidos e destacados vínculos entre a aprendizagem e ensino. Estamos convictos que esses conhecimentos têm o potencial de serem exploradas por meio de posturas e ações escolares, de modo adequa-las às particularidades da população brasileira, objetivando uma aprendizagem ativa, significativa, libertadora que atenda as perpectivas da Lei $10.639 / 03$.

PALAVRAS-CHAVE: Corporeidade. Afetividade. Educação Matemática. Etnomatemática. Africanidade.

\section{Mathematics, body and cultural resistance}

\begin{abstract}
We aimed at with this article to reorganize and to socialize some of our reflections about elaborations and mathematical thought that show in the communities of cultural resistance daily activities - black. For that, we ruled the analysis and the reflection in researchers' registrations, adopted to the program Etnomatemática of academic researches, who in
\end{abstract}

\footnotetext{
${ }^{1}$ Doutor em Educação. Prefeitura Municipal de São Paulo, São Paulo, São Paulo, Brasil. Universidade Federal de Mato Grosso, Pontal do Araguaia, Mato Grosso, Brasil. profvanisio@gmail.com

2 Doutora em Educação. Universidade Federal de Mato Grosso, Pontal do Araguaia, Mato Grosso, Brasil. wannara@ufmt.br.
} 
turn, they leaned over on cognitive and affectionate processes that they surface, in these institutions, through the corporeidade; of the word and of the gesture and of the solidary production. It is worth to highlight that the processes and manners are interpreted in this article, as ancestral knowledge with potential of they be incorporate to the school actions adapting them to the particularities of the Brazilian population, with the objective of a meaningful learning, it activates and libertadora that can assist to the perspectives of the Law 10.639/.03.

KEYWORDS: Corporeity. Affectivity. Mathematical Education. Ethnomathematics. Africanity.

\section{$* * *$ \\ Erro de português: quando o português chegou Debaixo duma bruta chuva vestiu o índio. Que pena! Fosse uma manhã de sol $O$ índio tinha despido o português.}

Oswald de Andrade

\section{Introdução}

No poema da epígrafe, "Erro de Português", Oswald de Andrade critica a forma como as culturas indígenas foram sobrepujadas pelos colonizadores, afirmando que se os portugueses não tivessem a visão embaçada pela neblina da intolerância e da ganância, talvez pudessem despir-se de seus preconceitos culturais e unirem-se aos nativos das terras de Pindorama, respeitando seu modo de ser e viver. O poema é inspirado na narrativa de Pero Vaz de Caminha, na famosa "Carta a el-Rei Dom Manoel sobre o achamento do Brasil", um dos primeiros documentos que trata do Brasil e do contato entre seus habitantes e os invasores europeus.

Tal como o documento citado, qualquer carta pessoal, em qualquer época, constituí-se em um texto muito próximo ao diálogo. Talvez por isso, com o advento da internet, seja via e-mails, facebooks, whatsApps, temos utilizado um gênero de escrita que se aproxima ao da carta pessoal, pois, da mesma forma que um carta, esse é "um gênero engendrado nas ideologias do cotidiano, sendo uma unidade funcional da língua, empregada em 
situações onde há ausência de contato direto entre interlocutores". (SILVA, 2013, p. 06). Mas a grande diferença entre as cartas tradicionais e as comunicações via e-mails é que as últimas permitem uma interação bem mais rápida.

Estando nós - os autores desse artigo - separados geograficamente por mais de mil quilômetros, temos mantido a interlocução por meio de e-mails e, ao decidirmos por esta escrita, optamos por manter as marcas dos diálogos que assim efetuamos. Então, ao longo do artigo, é possível perceber que, nesse tipo de elaboração, para dar continuidade à escrita, "não basta dar a palavra ao outro, é necessário aceitá-la e devolvê-la...” (GERALDI, 1990), permitindo, a cada vez, que as colocações de um dos interlocutores engendrem lembranças e reflexões no outro.

Esperamos que o formato que escolhemos para esse texto seja capaz de tornar-se um convite para o diálogo, de modo a cumprir nosso objetivo de contribuir para que os leitores reflitam conosco não só sobre as relações entre corpo e resistência cultural, mas também sobre os vínculos entre corpo e aprendizado matemático. Para encetar essa reflexão, resgatamos os resultados de pesquisas Etnomatemáticas que foram realizadas em comunidades quilombolas, rurais, de periferia urbana - percebidas como espaços de intervenção da população negra; mas também fazemos referência a estudos realizados em outras comunidades de resistência cultural. É a partir desses escritos que tecemos a argumentação de que o corpo, em suas dimensões performativa, gestual e afetiva, ocupa uma centralidade na criação, na incorporação e no uso de conhecimentos matemáticos. Então, concluímos acerca da importância de que esse vínculo seja reconhecido e valorizado no espaço escolar.

\section{Convite ao diálogo: e-mail de 10 de novembro}

Bom dia Wanderleya, envio esta correspondência na expectativa de juntos organizarmos alguns pensamentos acerca do corpo enquanto 
elemento de produção e expressão de aprendizagem "da matemática" na educação escolar. O convite se assenta primeiramente no fato de você ter acompanhado ativamente uma trajetória de estudo que culminou com a participação na minha banca de doutoramento, o que a transformou na mais frequente leitora e parceira desse meu projeto de vida.

Como é do seu conhecimento, parte do meu estudo de doutoramento se configurou pela ressignificação de registros de pesquisadores que se debruçaram sobre o raciocínio e os conhecimentos matemáticos que afloram de práticas cotidianas empreendidas em instituições de resistência cultural negras no Brasil. Retomando esse caminho, como ponto de partida, faço indagações acerca de contradições entre o uso do corpo nas atividades escolares e nas vivências com matemática na resistência cultural, conforme indiciam os registros de Vianna (2001), Jesus (2007) e Leão (2005). Estes autores, juntamente com Jesus (2006) e Costa (1998) que embora envolvidos com outras comunidades e instiruições de resistência, também destacam aspectos similares em seus estudos. Para tanto, penso que podemos nos fundamentar nas dimensões cognitiva, educacional e política do Programa Etnomatemática de pesquisas acadêmicas, conforme proposto por D’Ambrosio (2005).

Essa conjunção de fatores impõe a necessidade de primeiro descrever esses registros para que possamos detalhar melhor os objetivos e as possíveis similaridades entre os usos e os sentidos dados ao corpo, tanto no contexto da resistência cultural negra quanto em outras comunidades de resistência, que venham a ser objeto de estudo da Etnomatemática.

No primeiro registro em destaque, o professor Márcio Vianna (2001) relata uma série de ensaios da ala mirim de uma escola de samba do Rio de Janeiro, na qual a coreógrafa dividiu a dança (passo marcado) em oito movimentos. As escolas de samba são reconhecidas como instituições de resistência cultural popular "negra" e, neste caso, o pesquisador aproveitou a atividade para elaborar uma abordagem contextualizada para o ensino desobre frações. O pesquisador chamou atenção para o fato de o bom 
aproveitamento das crianças no trato com frações estar atrelado ao uso do corpo na experiência.

No segundo registro, a professora Elivanete de Jesus (2007) iniciou seu texto descrevendo uma unidade de medida, a tarefa - que compreende uma área de 30X30 varas - usada para mensurar o trabalho diário na roça de mandioca, na comunidade remanescente dos Kalungas do Riachão, no estado de Goiás. Neste caso, destaca-se que a comunidade foi tomada como uma instituição de resistência cultural negra e o fato de a autora chamar a atenção para a vara, que corresponde à altura de uma pessoa. Também ressalta-se na pesquisa, a fala de uma moradora que descreve: "uma tarefa é farinha para torrar o dia inteiro sem sobrar nada para o outro dia, mas também aproveita o dia inteiro na torragem", ou seja, uma tarefa de mandioca arrancada corresponde a um dia de farinha torrada, sem sobrar nem faltar nada.

Já no terceiro registro, o professor Jacinto Leão (2005, p. 120) descreve práticas e conhecimentos que afloram na lida dos habitantes do quilombo do Mola, em Itapocu no Estado do Pará, com a roça de mandioca. Segundo o autor:

Nos movimentos de ida e volta entre aqueles espaços, são (re)feitas conversas, contadas histórias, rememorizados e (re)visitados os significados dos textos com os contextos. Risadas e caçoadas, com espírito desinibido, não são tolhidas. Conversam com os olhos, com as mãos, ou seja, com seus corpos. Todavia, rir, na Idade Média, era proibido. Era uma atitude de atrevimento, de insubordinação. Os molenses compreendem os seus corpos.

O pesquisador, ao descrever a caminhada dos molenses entre as casas de farinha, desvela o modo como os conhecimentos ancestrais são resignificados e transmitidos às gerações dentro da comunidade. Em vista disto, o texto traz expressões que contribuem para compor as reflexões entre corporeidade e africanidade. Notemos que, ao lembrar que as risadas na Idade Média eram proibidas, Leão (2005) recorre a um marco da civilização 
eurocêntrica para situar as raízes de ações modernas de conformação contenção - das emoções e dos corpos em nome do racionalismo. Ele as contrapõe com as tradições africanas que inspiraram os habitantes do quilombo nas tomadas de atitude. O antagonismo é ilustrado pelo autor por meio de expressões que deixam transparecer, nas experiências de aprendizagem um uso intenso do corpo, dos sentimentos e das emoções: conversam com os olhos, com as mãos, ou seja, com seus corpos; era uma atitude de atrevimento, de insubordinação; os molenses compreendem os seus os corpos. Contudo, outros resultados desta pesquisa também dão conta de um uso ativo do corpo nas experiências de aprendizagem que ocorrem na resistência cultural.

Realmente, o destaque do pesquisador reporta uma experiência na escola da comunidade, mas ele se pautou na complexidade do diálogo entre a professora e os estudantes: P) quantas latas são um alqueire de farinha? R) são quarenta e oito latas - esta foi a resposta dos alunos. Como dito, a atividade se restringia à normalidade da sala de aula, mas ganhou corpo na afirmação de que o bom desempenho dos alunos se justifica - segundo as palavras da professora - porque "desde muito pequenos eles começam trabalhar com farinha, e, por isso, fica muito mais fácil eu trabalhar perguntando sobre”.

O quarto registro remete a uma comunidade indígena na área do Xingu - Posto Indígena Pavuru, no Mato Grosso. Nesse relato, o professor Cláudio L. de Jesus (2006) descreve a atitude de um morador ao confeccionar uma escada que levaria ao topo de uma caixa d'agua, no centro da aldeia. Embora tivesse conhecimento dos processos "formais de mensuração", o morador optou por usar como referência para a distância entre os degraus e a estatura de uma criança de três anos. A justificativa explicitada pelo construtor foi o fato desse padrão impedir a criança de ter acesso a um lugar potencialmente perigoso para a idade.

Ainda nesta trilha, querida professora, sua própria pesquisa de mestrado (COSTA,1998) relata e analisa o trabalho de ceramistas do Vale 
do Jequitinhonha em Minas Gerais, uma comunidade também interpretada como instituição de resistência cultural, justificada pelo modo de vida e pelo uso de técnicas ancestrais na produção de cerâmica. Destaca-se então, dentre outras atividades, a confecção de cinzeiros pelo fato de os ceramistas usarem a mão com o punho fechado como referência para definir o diâmetro do objeto, e ainda que nesta produção, os artesãos utilizam os dedos, de modo particular, para a demarcação dos três pontos equidistantes na borda da circunferência onde serão depositados os objetos fim.

Os cinco relatos evidenciam modos próprios das comunidades de resistência formularem e lidarem com conhecimentos e pensamento matemático - fundamentadas em concepções, valores e crenças distintas da razão cartesiana e demonstrando um uso ativo do corpo no trato com tais elaborações. Por isso, podendo concluir que o uso ativo do corpo, junto com outras práticas, pode ser um indicador relevante para as elaborações e as proposições da educação escolar.

\section{Estabelecendo o diálogo: e-mail de 10 de novembro}

Caro amigo, sinto-me instigada pelo seu desafio, visto que em trabalhos anteriores que desenvolvemos, a importância da corporeidade já tinha sido citada, mas não discutida em profundidade. Esse é um assunto que diz respeito a todos nós que algum dia frequentamos a escola formal; pois como estudantes de matemática o uso - ou melhor, a interdição do uso - do corpo no nosso próprio aprendizado da disciplina chama a atenção desde muito cedo. Você deve se lembrar que, quando ainda crianças, a partir de certo estágio, fomos proibidos de utilizar o corpo para aprender ou validar o uso de conceitos matemáticos. Na verdade, fomos ensinados e obrigados a separar de modo dicotômico o corpo e a mente. É certo que isso, num primeiro momento, causa embaraços e até mesmo sofrimentos, mas com o passar do tempo, começamos a naturalizar a situação, pelo menos comigo foi assim, até 1996. 
Porque tenho certeza dessa data? Simples, porque foi nesse período, quando participava do SHEM - Seminário de História e Educação Matemática, que o líder do grupo, o Prof. Eduardo Sebastiani Ferreira, nos incitava a reconhecer a importância do uso do corpo na construção do conhecimento matemático. Participavam do grupo Alexandrina Monteiro, Cláudio de Jesus - cujo trabalho de mestrado você lembrou -, Franceli Freitas, Jaqueline Mendes, Pedro Paulo Scandiuzzi e eu, dentre outros.

Naquele período, eu estava desenvolvendo minha dissertação de mestrado e meus estudos eram orientados pela Profa. Maria do Carmo dos Santos, enquanto a pesquisa do Scandiuzzi era orientada pelo Prof. João Frederico Meyer; mas o Prof. Sebastiani era também nosso grande interlocutor. Foi nessa condição que ele contribuiu com Scandiuzzi (1997) na análise da forma como os Lahatua Otomo - indígenas que habitam no Parque do Xingu/MT - utilizam as mãos e os pés para expressar e operar números; visto que o fazem de modo bem diverso do que ocorre em outros contextos culturais. Talvez também tenha sido a interferência das discussões estabelecidas naquela época que tenham levado Jesus (2006) a, posteriormente, atentar-se para o uso do corpo da criança indígena como parâmetro para estabelecer a distância entre os degraus da escada.

De todo modo, foi por meio do Prof. Sebastiani que tivemos contato com a pesquisa de Maria Queiroga Amoroso Anastacio, que naquele período era sua orientanda de doutorado e desenvolvia um estudo no qual explicitava o modo "como a Matemática, apesar de feita por homens e mulheres historicamente encarnados, parece planar num mundo pré-fabricado" (ANASTACIO, 1999, resumo). Na tese, ela chama atenção para o fato de que "o pensamento ocidental abandonou o desafio da experiência de ambiguidade que o corpo oferece, ao se experimentar sujeito que conhece ao mesmo tempo em que é objeto que se deixa conhecer" (ANASTACIO, 1999, p.10). Mas, como você assinala, se na escola buscamos esse afastamento entre corpo e matemática, em comunidades de resistência negras e 
indígenas, a relação entre corpo, aprendizagem e produção de conhecimentos (etno)matemáticos parece ser reconhecida e utilizada.

De modo especial, no estudo citado, Anastacio (1999) desenvolveu três ensaios. No primeiro deles, a autora usa a história das ideias matemáticas para descrever como se deu a constituição da matemática como ciência caracterizada pela abstração, pelo uso da mente em detrimento do corpo. No segundo ensaio, Anastacio (1999) descreve sua compreensão das ideias expostas por Merleau-Ponty acerca do corpo, da linguagem, do conhecimento, do espaço e da temporalidade. Então, ela as utiliza para falar da possibilidade de uma racionalidade distinta da cartesiano-kantiana. No terceiro ensaio, a pesquisadora articula as colocações expostas anteriormente, congregando-as com as ideias de Paulo Freire e as teorizações sobre a Etnomatemática. Eu creio que esse aporte teórico pode ser útil para dar sequência à discussão que você tomou como pauta para o momento, de modo a compreender melhor a relação entre corpo e cognição a partir de racionalidades não cartesianas que são cultivadas nas comunidades descritas nos estudos etnomatemáticos que você citou.

\section{Conformação X libertação o corpo: e-mail de 20 de novembro}

Querida professora, percebi que Maria Queiroga assume uma postura bastante crítica à Matemática que se caracteriza como uma ciência da modernidade e que prima pela abstração e uso da mente em detrimento do corpo. Ao mesmo tempo, ela opta por outro modelo (etno)matemático de produzir, pensar e utilizar os conceitos da mesma. Neste aspecto, a tese da pesquisadora se alinha aos fundamentos do estudo de Costa e Silva (2016) acerca das emoções e dos sentimentos na aprendizagem de matemática para analisar as diferenciações no desempenho das crianças negras na escola. No estudo, recorremos a Falcão (2003) que demonstra a presença, na emergência da Psicologia da Educação Matemática brasileira, de pesquisas 
que se distribuíam em três eixos orientadores: a matemática dos matemáticos, a matemática escolar e a matemática extraescolar.

Ele, descreve que os dois primeiros eixos incorporaram contratos didáticos, atividades e conteúdos matemáticos pensados e propostos exclusivamente para o contexto da sala de aula. Uma percepção que revela o predomínio do cientificismo e abtracionismo na Educação Matemática brasileira, ou seja, uma opção dos educadores matemáticos por abordagens deslocadas da realidade e das vivências cotidianas das pessoas e suas comunidades. Também revela uma herança da educação jesuítica que de modo indireto limita os movimentos dos corpo nos processos de aprendigem escolares.

Apenas a matemática extraescolar, asseverou o autor, incorporava elaborações vinculadas ao cotidiano de grupos culturalmente diferenciados, assim como as particularidades que envolvem o formular, acumular e difundir conhecimentos e processos cognitivos que deles emergem, ou seja, os estudos fundamentados no programa Etnomatemática de pesquisas acadêmicas. Do mesmo modo, os estudos apresentados ao longo dos Congressos de Pesquisadoras(es) Negras(os)-COPENES, revelam uma clara opção pelo programa Etnomatemática como aporte teórico ( SILVA, 2014).

É possível perceber também que, no segundo ensaio, Anastacio (1999) trata mais especificamente do corpo enquanto expressão de linguagem e conhecimento sobre espaço e temporalidades, além de suas representações em contextos distintos ao cartesiano-kantiano. Ao que lembro, nós também percebemos contradições acerca das relações entre corpo e conhecimento ao analisar a obra "A microfísica do poder" (FOUCAUT, 1997), que inclui a escola, a prisão e o hospício entre as microinstituições de regulação do poder. O autor afirma que elas convergem para a doutrinação e conformação dicotômica de corpo e mente, segundo um ideal ocidental de humano e sociedade. Ele revela ainda que este processo reverbera nos seus muros, grades, filas e corredores definindo movimentos, comportamentos, valores, 
crenças, lugares sociais e até posturas adequadas à aprendizagem "de matemática”.

Por fim, no terceiro ensaio, Anastacio (1999) assume a perceptiva freireana como fundamento na análise sobre a dicotomia entre corpo e mente. Também neste caso nossa reflexão seguiu um rumo semelhante ao tomar como referência a afirmação de que a "educação [que é concebida] como prática da liberdade, ao contrário daquela que é prática da dominação, implica a negação do homem abstrato, isolado, solto, desligado do mundo, assim como uma realidade ausente nos homens" (FREIRE, 2006a, p. 70 apud COSTA e SILVA, 2016). Nossa compreensão acerca do ato políticopedagógico é de que a escola deve considerar as diferenças nos processos de organização e sistematização do pensamento e os conhecimentos culturais como complementares nas abordagens escolares. Aliás, esta síntese resume a própria perspectiva de educação freireana, uma vez que para o autor "a unidade dialética entre a leitura do mundo e a leitura da palavra possibilita, cada vez mais, o atuar e o pensar sobre a realidade, suscitando a sua transformação" (FREIRE, 2006, p.106).

Concluindo, as análises de Costa e Silva (2016) e de Anastacio (1999) indiciam que essa dicotomia é quem sustenta as crenças e as convicções de educadores "matemáticos" - herdadas do idealismo matemático, da tradição jesuítica e das teorias raciais do século XVIII - no tocante à necessidade de conter movimentos do corpo e fala para melhorar a concentração e a abstração dos alunos até atingir os níveis mínimos necessários à aprendizagem "da disciplina".

\section{Humanizar a matemática pelo corpo: e-mail de 03 de dezembro}

De fato, meu amigo, as ideias humanizadoras de Freire contribuem para esse exercício de reflexão sobre o papel do corpo e da afetividade na constituição do pensamento de resistência, como bem destacou Anastacio (1999). Você também tem razão ao pontuar que categorias tão caras à 
Foucault tais como: saber, poder, subjetividade, linguagem e discurso podem ser importantes para essas análises. Então, lembrando dos estudos etnomatemáticos realizados junto às comunidades indígenas, quilombolas, ou mesmo dos ceramistas, é possível reconhecer que esses contextos são inspiradores de análises acerca da submissão das pessoas a sutis e produtivos mecanismos de poder que estão presentes nas escolas. $\mathrm{Na}$ verdade, parece-me que, mesmo que não tenha utilizado Foucault como aporte teórico, em sua tese, você já começava a se perguntar: como o modo das comunidades negras se relacionarem com o corpo e a afetividade pode inspirar estratégias de resistência úteis para repensarmos o poder visível da interdição que, na escola, nas aulas de matemática, separam corpo e mente?

Desse modo, entendo que, nessa nossa "conversa", você recolocou a questão: por que, como professores de matemática, não temos dado a devida atenção ao fato de que, ao considerarmos apenas a racionalidade cartesianokantiana, temos imposto coerções e restrições que os estudantes principalmente os de origem quilombola e indígena - sentem na pele? Por que, nas escolas, ainda perdura a ausência de preocupação com as práticas matemáticas "concretas", vividas por essas pessoas que, usando em conjunto corpo e mente, orientadas por sua afetividade, lutam para terem suas especificidades (re)conhecidas? Por que nós, professores de matemática, muitas vezes, mantemos certa negligência com relação aos esforços desses grupos para a transformação das estruturas escolares vigentes, sobretudo no que se refere ao ensino da nossa disciplina? Será que, ainda hoje, o ensino da matemática escolar precisa calar, rechaçar, colocar na penumbra a materialidade da relação existente entre corpo e mente, ou entre cognição e afetividade, relações essas tão caras aos estudantes negros e indígenas? 


\section{A afetividade, corpo, aprendizagem e reconhecimento do valor da produção solidária, da palavra e do gesto: e-mail de 11 de dezembro}

Querida Wanderleya, suas indagações me impõem retomar, com mais detalhe, às percepções sobre africanidade a que me referi na tese de doutoramento, mais precisamente quando recorri a Munanga (2007) e Oliveira (2003) para descrever as manifestações da africanidade brasileira. Ambos interpretam que, apesar da enorme diversidade que constitui o continente negro, existem conceitos, valores e crenças ancestrais que se manifestam nas diferentes nações e grupos étnico-culturais. A conjugação desses fatores dão à Africa um aspecto próprio que caracteriza a noção de africanidade que se configura como herança ancestral de um povo que, ao desembarcar no Brasil, dispunha apenas da memória e do corpo para ressignificar tais conceitos, valores e crenças que hoje sustentam um dos três pilares do olhar brasileiro.

No que diz respeito mais especificamente às reelaborações e à transmissão desses conhecimentos, Munanga(2007) afirma que elas emergem cotidianamente nas instituições de resistência, embebidas em processos que inscrevem em si modos próprios de estar no mundo - herdado das civilizações africanas - por meio da corporeidade; da palavra e do gesto; da organização e estruturação da família, do trabalho e do poder, da sociedade e da solidariedade na produção. São estas manifestações e modos que retroalimentam a resistência, as identidades e anseios de sobrevivência e transcendência das populações negras, além de sustentar as lutas pela superação dos processos de inclusão perversa a que têm sido submetidas essas populações na sociedade e na educação escolar brasileira.

$\mathrm{Na}$ verdade, os relatos sobre o uso do corpo como elemento fundamental à aquisição e à transmissão de conhecimentos são recorrentes em vários estudos, inclusive naqueles que se referem a aprendizagem em sala de aula. Assim, como pontuam Sabino e Lody (2011, p.80): 
São muitas as ação repetidas das tradições ancestrais, outras foram adaptadas, algumas criadas ou fundidas, mas têm sempre no corpo possível, no corpo do trabalho, o principal elemento-base para realizar, nos momentos permitidos, a celebração da pessoa com a sua história (...).

Entretanto, pontua Clareto (2013), pensar na nossa relação com os corpos remete aos:

...currículos que se atualizam na aula, nos corpos de alunos e professor, no espaço da sala de aula, através de gestos, falas, manifestações cognitivas, sensibilidades, afetos, enfim, expressões diversas dos processos de aprender. Não uma aprendizagem de conteúdos - que envolve o professor como aquele que ensina e o aluno como aquele que aprende, mas professor a alunos aprendendo, inventando uma matemática e se inventando, (CLARETO, 2013, p. 4).

Do que foi dito nos parágrafos anteriores, destaca-se o corpo - tanto as ações libertadoras, nas quais há um uso ativo, quanto as ações conformadoras, na quais quais há uma contenção -, como um relevante fator de afetividade nas experiências de aprendizagem. Por sua vez, a recorrência de um uso ativo na resistência reafirma a tese do mesmo, enquanto manifestação da africanidade brasileira. É sob esse ponto de vista que interpretamos que o corpo deve ser considerado, ou seja, pensado enquanto um recurso relevante à aprendizagem no planejamento e nas atividades escolares.

Complementarmente, também destaco que o valor dado à palavra, ao gesto e à produção solidária também são posturas/hábitos irraigados nas comunidades estudadas por Costa (1998), Jesus (2006), Jesus (2007) e Leão (2005) e que são relevantes nos processos de aprendizagem utilizado nesses contextos. Assim, tal como a corporeidade, essas outras manifestações são 
relevantes à afetividade e à prendizagem e o respeito a elas certamente ajudará na transformação das práticas curriculares, tendo em vista que a proposta se pauta na lei 10.639/03. Por isso, faz-se oportuno lembrar a colocação de que é:

Pelo uso da palavra e gesto, o homem pretende apropriar-se de uma parte importante da força que irriga o universo e utiliza essa força para suas próprias finalidades. As palavras são eficazes porque são carregadas de forças. A palavra, na África, pode curar como pode matar, porque é carregada de uma força vital importante. (MUNANGA, 2007).

Entretanto, penso que o valor dado a palavra deve ser compreendido não somente como manifestação de resistência cultural negra brasileira, mas como um fenômeno comum às sociedades e culturas de tradição oral. Afinal, as pesquisas que aqui lembramos [(SCANDIUZZI, 1997) (COSTA, 1998), (LEÃO 2005), (JESUS, 2006) e (JESUS 2007)] foram capazes de demonstrar que para as comunidades estudadas, a palavra e gesto têm valor e significado distinto das sociedades filiadas exclusivamente à concepção moderna de mundo.

É por meio da palavra e do gesto que as sociedades tradicionais mantêm vivos seus princípios e fundamentos, pois estes são os recursos mais recorrentes nos processos de aquisição e de transmissão de conhecimento. No caso das comunidades de origem africanas, a palavra e o gesto são fundamentais também para as manifestações de religiosidade e como forma de expressão do sagrado. Ainda neste sentido, a expressão transcrita acima - "a palavra, na África, tanto pode curar como pode matar, porque é carregada de uma força vital importante" - parece inspirar-se em um ditado que versa sobre o compromisso das culturas africanas e diásporicas com a verdade nas narrativas, reafirmando a conviç̧ão que o mal uso da palavra pode destruir conceitos, valores e crenças ancestrais. Diante do exposto, firma-se a convicção quanto ao fato do uso da palavra e do gesto também 
constituírem elementos a ser considerados na intenção de constituir práticas escolares mais adequadas à população brasileira.

Em paralelo, observe que a organização do trabalho, evidenciada principalmente na pesquisa de Leão (2005) na comunidade do Mola/PA, revela que o processo produtivo nos contextos e ambientes de africanidade faz emergir a solidariedade ${ }^{3}$ como herança das civilizações africanas na resistência negra. Este modelo encontrou no Brasil um solo fértil para sua ressignificação e assentamento em função das circunstâncias de inserção perversa a que foi submetida a população negra na sociedade. Dito de outro modo, as condições oferecidas pelo escravismo às senzalas impuseram a cooperação e a solidariedade como estratégias de sobrevivência, transcendência e produção.

Outras pesquisas em etnomatemática demonstram que o solidarismo na produção e na organização do trabalho emergem na resistência negra brasileira como parte de uma trama que repercute sobre um modo próprio de olhar para o mundo. Este fato leva à conclusão que tanto o trabalho como a produção solidária se manifestam como elementos de africanidade brasileira. Contudo, há que se pontuar que práticas de produção solidária também foram observadas em outras comunidades de resistência, como é o caso dos ceramistas do Vale do Jequitinhonha (COSTA, 1998).

Em síntese, nas comunidades remanescentes, o uso do corpo, a produção solidária, o valor dado à palavra e ao gesto, são competentes instrumentos de aprendizagem, além de constituirem relevantes elementos na constituição da afetividade. Por isso, em resposta à sua questão: "Será que, ainda hoje, o ensino da matemática escolar precisa calar, rechaçar, colocar na penumbra a materialidade da relação existente entre corpo e mente, ou entre cognição e afetividade, relações essas tão caras aos estudantes negros e indígenas?", eu diria que não.

\footnotetext{
${ }^{3}$ A palavra "solidariedade" é aqui interpretada no sentido das responsabilidades do indivíduo em relação a uma coletividade à qual pertence e de cuja manutenção se beneficia, como a família. Fazendo com que este sinta-se integrante de uma mesma comunidade interdependente.
} 
Sob o meu ponto de vista, o aprendizado que obtivemos junto a todas as pesquisas aqui citadas deve recompor o olhar do educador matemático, levando-o a perceber a importância de constituir outras práticas escolares, nas quais as relações entre corpo, aprendizado, afetividade e cognição sejam potencializadas. Mas, para concluir minhas considerações, vou tomar posse de um trecho da 'Carta para Caroline", escrita pelo roteirista Eric Roth na sua adaptação do conto de F. Scott Fitzgerald "The Curious Case of Benjamin Button" :

Podemos encarar a vida de forma positiva ou negativa, espero que encare de forma positiva; espero que veja coisas que surpreendam você; espero que sinta coisas que nunca sentiu antes; espero que conheça pessoas com ponto de vista diferente; espero que tenha uma vida da qual você se orgulhe. E se você descobrir que não tem, espero que tenha forças para conseguir começar de novo.

Parece-me que essa carta também pode ser endereçada aos educadores matemáticos, encorajando־os a mudar concepções e práticas escolares no ensino de sua disciplina...

\section{Considerações sobre cartas e utopias: e-mail sem data definida}

A carta de Pero Vaz de Caminha para o rei português Dom Manoel, a carta de despedida de Getúlio Vargas, os bilhetes de Janio Quadros... As cartas de amor de Frida Kahlo para Diego Rivera, a carta de Gandhi pedindo a Hitler para evitar a guerra... Cartas, missivas, bilhetes que, ao longo da história, comunicaram fatos, sentimentos, desesperanças, esperanças ...

Hoje, facebooks, whatsApps e e-mails têm cumprido esse papel e foi utilizando esses últimos que elaboramos esse texto, no qual o objetivo foi discutir a relação entre corpo, cognição, aprendizado e afetividade. Tomando como lócus especial o contexto da educação matemática, lembramos várias 
pesquisas etnomatemáticas que tiveram lugar em comunidades de resistência, notadamente, negras e indígenas, culturas de tradição oral. Em conjunto, esses trabalhos evidenciaram o intenso uso do corpo, dos sentidos, dos sentimentos e das emoções na construção, na aprendizagem e no uso de conhecimentos (etno)matemáticos e, segundo nossas análises, esses aspectos podem inspirar a adoção de posturas e de atitudes na educação escolar.

Consideramos que essa é uma possibilidade relevante, sobretudo quando recordamos as colocações do sociólogo polonês Zygmunt Bauman. Também esse pensador concorda com Foucaut na avaliação de que a educação escolarizada é uma fabricante de corpos dóceis, disciplinados e eficientes (BAUMAN, 2009). Contudo, ele sugere que cabe aos educadores estimular, na juventude, características que ficaram prejudicadas com a utilização da tecnologia e com o fato de que a juventude ser tratada como um objeto publicitário capaz de criar, consolidar ou modificar o posicionamento de marcas, produtos e de instituições - como se, na modernidade "líquida", o corpo fosse sobretudo um mostruário. Além disso, aponta o autor, os elos que entrelaçavam as escolhas individuais em projetos de ação coletivos se esvaneceram dando lugar ao individualismo e ao consumismo; orientando-se por esse modo de pensar e agir, os jovens afastam-se da cooperação e da solidariedade. Nesse contexto, torna-se necessário legitimar novamente os sentimentos e as emoções.

Como argumentamos ao longo do texto, essa sugestão é corroborada pelas práticas de aprendizagem adotadas nas comunidades de resistência cultural, que também apontam para a importância do gesto e da palavra, assim como da produção colaborativa. É verdade que não há uma resposta pronta que afaste as angústias e tormentos das crianças e adolescentes que são continuamente instigados a separar corpo e mente, razão e emoção, matemática escolar e etnomatemática. Mas, Bauman lembra que: 
Nossas vidas, quer o saibamos ou não e quer o saudemos ou lamentemos, são obras de arte. Para viver como exige a arte da vida, devemos, tal como qualquer outro tipo de artista, estabelecer desafios que são (pelo menos no momento em que estabelecidos) difíceis de confrontar diretamente; devemos escolher alvos que estão (ao menos no momento da escolha) muito além de nosso alcance, e padrões de excelência que, de modo perturbador, parecem permanecer teimosamente muito acima de nossa capacidade (pelo menos a já atingida) de harmonizar com o que quer que estejamos ou possamos estar fazendo. Precisamos tentar o impossível. E, sem o apoio de um prognóstico favorável fidedigno (que dirá de certeza), só podemos esperar que, com longo e penoso esforço, sejamos capazes de algum dia alcançar esses padrões e atingir esses alvos, e assim mostrar que estamos à altura do desafio (BAUMAN, 2009b, p. 31).

Então, talvez possamos tomar uma atitude que não reproduza o "erro de português" do qual nos falou Oswald de Andrade, mas tomando referências a sabedoria das comunidades negras e indígenas, como inspiradoras na constituição de um ensino de matemática entalhado em uma educação escolar que considere o ser humano na sua complexidade e diversidade. Ainda, que tal ousadia leve a utopia de pensar uma escola na qual muros, paredes e grades não impeçam as crianças de serem crianças, pois conforme a narrativa de uma amiga "na escola indígena que ela conheceu as crianças entram e saem da aula por portas e janelas indistintamente" e sem serem tomadas como marginais em potencial, mas como crianças explorando as potencialidades de sua infância.

\section{Referências}

ANASTÁCIO, M. Q. A. Três Ensaios numa articulação sobre a Racionalidade, o Corpo e a Educação na Matemática. Tese de Doutorado. Campinas: UNICAMP, 1999. 
BAUMAN, Z. A sociedade individualizada: vidas contadas e histórias vividas. (J. Gradel, Trad.). Rio de Janeiro: Jorge Zahar, 2009. (Original publicado em 2001).

Arte da vida. Rio de janeiro: Jorge Zahar Ed., 2009.

CLARETO, Sônia Maria. Matemática como acontecimento na sala de aula. anais da $36^{\text {a }}$ Reunião Nacional da ANPEd. Goiânia, GO, set. /out. 2013.

COSTA, W. N. G. Os ceramistas do Vale do Jequitinhonha: uma investigação etnomatemática. Dissertação (Mestrado em Educação) - Universidade Estadual de Campinas - UNICAMP. Campinas, SP, 1998.

COSTA, W. G.; SILVA, V. L. Á sombra do baobá: a cultura negra na educação etnomatemática. Educação em Foco, Juiz de Fora, UFJF, v. 21, n. 3, p. $105-120$, set. /dez. 2016.

D'AMBROSIO, U. Etnomatemática: o elo entre as tradições e a modernidade. Belo Horizonte: Autêntica, 2005.

FALCÃO, J. T. Psicologia da Educação Matemática: uma introdução. Belo Horizonte: Autêntica, 2003.

FREIRE, P. Pedagogia da autonomia. Saberes necessários à prática educativa. 33. ed. São Paulo: Paz e Terra, 2006a.

.Pedagogia da Esperança: um reencontro com a pedagogia do oprimido. $13^{\mathrm{a}}$ ed. Rio de Janeiro: Paz e Terra, 2006.

FOUCAULT, M. Microfísica do Poder. 11ª ed., Rio de Janeiro: Graal, 1997.

GERALDI, J. W. Portos de passagem. São Paulo: Martins Fontes, 1990.

JESUS, C. L. A etnomatemática das práticas cotidianas no contexto de formação de profissionais indígenas no Xingu. 2006. 1v. 123p. Dissertação (Mestrado em Educação) - Universidade De São Paulo

JESUS, E. A. As artes e as técnicas do ser e do saber/ fazer em algumas atividades no cotidiano da comunidade kalunga do riachão. 2007. 119 f. (Dissertação de Mestrado). Universidade Estadual Paulista. Rio Claro, 2007.

MUNANGA, K. O que é africanidade. Biblioteca entre livros, São Paulo, Edição especial $n^{\circ} 6,2007$.

OLIVEIRA, D. O. A cosmovisão africana no Brasil: elementos de uma filosofia afrodescendente. 3 ed. Curitiba: Editora Gráfica Popular, 2003. - Também em $<$ http://pt.scribd.com/doc/164472017/Cosmovisao-Africana-no-Brasil>Acesso em: 11/12/2017.

LEÃO, J. P. P. Etnomatemática Quilombola: as relações dos saberes da matemática dialógica com as práticas socioculturais dos remanescentes de quilombo da Mola- 
Itapu/PA. 2005. 157 f. (Dissertação de Mestrado) Universidade Federa do Pará. Belém, 2005.

SABINO,J; LODY,R. Danças de matriz africana: Antropologia do movimento. Rio de Janeiro: Pallas, 2011.

SCANDIUZZI, P. P. A dinâmica da contagem de Lahatua Otomo e suas implicações educacionais: Uma pesquisa em Etnomatemática. Dissertação (Mestrado em Educação Matemática) - UNICAMP, Campinas, 1997

SILVA, M.S.B. O gênero carta do leitor na mídia impressa: dialogismo, responsividade e avaliação. Revista de Divulgação Científica em Língua Portuguesa, Linguística e Literatura. Ano 09, n.17, $2^{\circ}$ Semestre de 2013. Disponível em http://www.letramagna.com/17_9.pdf. Acesso em outubro de 2017.

SILVA, V. L. Africanidade, matemática e resistência (Tese de Doutorado). Faculdade de Educação, Universidade de São Paulo, São Paulo, 2014.

VIANNA, M. A. A escola da Matemática e a escola do samba: um estudo etnomatemático pela valorização da cultura popular no ato cognitivo. Rio de Janeiro: Universidade Santa Úrsula, 2001. (Mestrado). Orientador: Prof. Dr. Eduardo Sebastiani Ferreira e $\operatorname{Prof}^{a}$ Dr $^{a}$ Sônia Borges.

O curioso caso de Benjamin Button. Direção: David Fincher. Roteiro: Eric Roth. Estados Unidos: Paramount, 2008. 1 DVD (165 min.), som, color 